\title{
Sistem SKKM Dengan Metode Hitung Multi Factor Evaluation Process Berdasarkan IAPS 4.0
}

\author{
SKKM System with Multi Factor Evaluation Process Calculation Method Based on \\ IAPS 4.0 \\ Muhammad Hatta*1, Renny Wahyuni' ${ }^{2}$, Lena Magdalena ${ }^{3}$ \\ ${ }^{1,2,3}$ Program Studi Sistem Informasi, Fakultas Teknologi dan Informasi, Universitas Catur Insan \\ Cendekia Cirebon \\ e-mail: ${ }^{* 1}$ muhammad.hatta@cic.ac.id ${ }^{2}$ rennuiwahyuni@gmail.com, ${ }^{3}$ lena.magdalena@cic.ac.id
}

\begin{abstract}
Abstrak
Setiap Universitas harus bias mewadahi kegiatan-kegiatan yang dapat mengembangkan bakat dan potensi mahasiswa baik dibidang keorganisasian, olahraga, seni, budaya dan kegiatan non akademik lainnya diwadahi dalam suatu lembaga keorganisasian kemahasiswaan, Setiap Universitas harus senantiasa mendorong mahasiswa agar mengikuti kegiatan-kegiatan yang dapat menggali minat bakat dan kompetensi yang diselenggarakan internal maupun eksternal kampus guna memperoleh nilai tambah bagi mahasiswa disamping nilai akademik dan kampus dalam memenuhi syarat salah satu kriteria Instrumen Akreditasi Program Studi 4.0 yaitu Luaran dan Capaian Tridharma.Untuk itu setiap Universitas perlu memberikan apresiasi setiap kegiatan ekstrakurikuler dan non kurikuler dalam bentuk Satuan Kredit Kegiatan Mahasiswa (SKKM). Penelitian ini bertujuan merancang dan membangun sistem satuan kredit kegiatan mahasiswa dengan metode hitung multifactor evaluation process (MFEP) yang berdasarkan pada salah satu kriteria Instrumen Akreditasi Program Studi (IAPS) 4.O. Sistem yang dikembangkan berbasis WEB dengan pengembangan perangkat lunak menggunakan bahasa pemrograman PHP dan MySQL. Hasil pengembangan Sistem Satuan Kredit Kegiatan Mahasiswa (SKKM) dapat mempermudah Kepala Bagian Kemahasiswaan dan Kepala Program Studi dalam melakukan pengolahan data dan dokumen elektronik terkait kredit kegiatan mahasiswa.
\end{abstract}

Kata kunci SKKM,MFEP, IAPS 4.0.

\begin{abstract}
Each University must be able to accommodate activities that can develop students' talents and potentials in the fields of organization, sports, arts, culture and other non-academic activities which are accommodated in a student organizational institution. Each University must always encourage students to participate in activities that can explore interest in talent and competence held internally and externally in the campus in order to gain added value for students in addition to academic and campus values in meeting the requirements of one of the Study Program Accreditation Instrument 4.0 criteria, namely the Outcomes and Achievements of Tridharma. For that every University needs to give appreciation to each extracurricular and non curricular in the form of a Student Activity Credit Unit (SKKM). This study aims to design and build a system of student activity credit units using the multifactor evaluation process (MFEP) method which is based on one of the criteria of the Study Program Accreditation Instrument (IAPS) 4.0. The system developed is based on WEB with software development using the PHP and MySQL programming languages. The results of the development of the Student Activity Credit Unit System (SKKM) can facilitate the Head of Student Affairs and the Head of the Study Program in processing data and electronic documents related to student activity loans.
\end{abstract}

Keywords SKKM,MFEP, IAPS 4.0

\section{PENDAHULUAN}

Satuan Kredit Kegiatan Mahasiswa (SKKM) merupakan salah satu penilaian suatu pengembangan kegiatan kemahasiswaan yang diikuti oleh mahasiswa [1]. Penilaian terhadap SKKM akan dilihat berdasarkan jenis kegiatan yang diikuti oleh mahasiswa baik yang diselenggarakan didalam ataupun diluar kampus. Dimana kegiatan-kegiatan tersebut diharapkan

Informasi Artikel:

Submitted: Agustus 2020, Accepted: September 2020, Published: November 2020

ISSN: 2685-4902 (media online), Website: http://jurnal.umus.ac.id/index.php/intech 
dapat menggali minat, bakat, dan kompetensi yang dimiliki mahasiswa guna memperoleh nilai tambah selain kegiatan akademik yang didapatkan secara formal. Kegiatan mahasiswa tersebut juga dapat membantu Universitas untuk memenuhi salah satu persyaratan Instrumen Akreditasi Program Studi (IAPS) kriteria kesembilan mengenai Luaran dan Capaian Tridharma yang dikembangkan oleh BAN-PT yang selanjutnya akan menjadi IAPS 4.0 versi 2018 yang telah efektif diterapkan pada 1 Januari 2019. Untuk itu, setiap Universitas perlu memberikan apresiasi terhadap setiap kegiatan ektrakurikuler dan non kurikuler dalam bentuk Satuan Kredit Kegiatan Mahasiswa (SKKM) sebagai salah satu bentuk pengakuan dan penilaian terhadap mahasiswa atas partispasinya dalam kegiatan ektrakurikuler dan non kurikuler.

Bagian kemahasiswaan merupakan salah unit yang bertugas dan bertanggungjawab dalam proses pengolahan data kredit kegiatan mahasiswa. Pada kenyataannya, meningkatnya jumlah kegiatan dan partisipasi mahasiswa dalam kegiatan ekstrakurikuler dan nonekstrakurikuler berdampak pada lambatnya proses penilaian penghargaan atas partisipasi mahasiswa sehingga mengakibatkan lamanya proses pelaporan yang diberikan. Berdasarkan hal tersebut, maka penelitian ini bertujuan untuk merancang suatu sistem informasi SKKM melalui pendekatan multifactor evaluation process (MFEP) untuk menghitung total poin yang diperoleh mahasiswa dalam kegiatan non akademiknya berdasarkan aturan IAPS 4.0. Metode MFEP dipilih karena metode ini akan menggunakan pendekatan secara kolektif dalam proses pengambilan keputusannya berdasarkan bobot kriteria terpenting [2], [3].

Beberapa penelitian terdahulu yang penulis jadikan referensi diantaranya mengenai penerapan fuzzy Mamdani yang digunakan untuk menentukan mahasiwa yang aktif dan tidak aktif dalam kegiatan non akademik mahasiswa melalui SKKM [1]. Selain melalui pendekatan beberapa metode, pembuatan suatu system informasi pengolahan data SKKM pernah dilakukan di Universitas Respati Yogyakarta khususnya di Fakultas Sains dan Teknologi[4] dan di Fakultas Ilmu Komputer Universitas Brawiyaja [5] dimana keduanya membuat suatu informasi SKKM / SKM secara online tanpa harus melakukan pemberkasan fisik ke Bagian Kemahasiswaan. Keberhasilan atas usabilitas dan acceptability range yang tinggi serta dapat diterima dengan baik juga ditunjukkan terhadap kemudahan penggunaan sistem informasi

Satuan Kredit Partisipasi (SKP) mahasiswa Udayana khususnya fakultas Teknik dalam penerapan SKP[6]. Pembuatan sistem informasi SKP juga diterapkan di Universitas Islam Indonesia, dimana sistem ini digunakan untuk tingkat Fakultas/Prodi, NonProdi/DPAI, Namun berdasarkan hasil uji UEQ (User Experience Questionnaire) pemberian nama beberapa fitur masih perlu perbaikkan agar system dapat bersifat user friendly [7].

\section{METODE PENELITIAN}

\section{Metode Penelitian}

Pada penelitian ini penulis akan menggunakan pendekatan secara protoype, karena mampu mendefinisikan secara jelas obyek keseluruhan dari software yang akan dibuat melalui perancangan kilat sehingga dapat tergambar secara jelas software yang akan dibuat[8]. Adapun penerapan langkah prototype tersebut terlihat pada Gambar 1.

Berdasarkan Gambar 1, maka pendekatan multifactor evaluation process (MFEP) diterapkan pada saat pembuatan prototype, dimana sistem akan menghasilkan total nilai yang dihasilkan. Selanjutnya sistem akan dievaluasi oleh bagian kemahasiswaan, jika masih terdapat kesalahan maka sistem akan diperbaiki namun jika telah sesuai dengan standar IAPS 4.0 maka sistem dapat digunakan sebagai penentuan nilai mahasiswa untuk SKKM. Dalam penilaian SKKM ada beberapa indikator yang dijadikan alat ukur untuk penilaian SKKM diantaranya adalah :

1. Bidang Akademik : merupakan bidang penilaian yang melibatkan kepanitian dan partisipasi mahasiswa dalam pembuatan atau penyajian makalah / moderator ilmiah, melakukan penelitian / karya tulis, seminar dan workshop. 
2. Bidang Minat Bakat dan Olahraga : merupakan bidang penilaian yang melibatkan kepanitian dan partisipasi mahasiswa dalam keikutsertaan dalam turnamen / kompetisi minat dan bakat yang diselenggarakan oleh kampus maupun diluar kampus.

3. Bidang Pengabdian Masyarakat : merupakan bidang penilaian yang melibatkan kepanitian dan partisipasi mahasiswa dalam keikutsertaan mahasiswa pada pengabdian masyarakat, bakti sosial, donor darah serta kegiatan-kegiatan pengabdian kepada masyarakat.

4. Kegiatan Wajib : merupakan bidang penilaian yang melibatkan kepanitian dan partisipasi mahasiswa dalam kegiatan wajib yang diikuti oleh mahasiswa seperti jalan sehat, pentas musik serta gema mahasiswa teknologi informasi (GMTI).

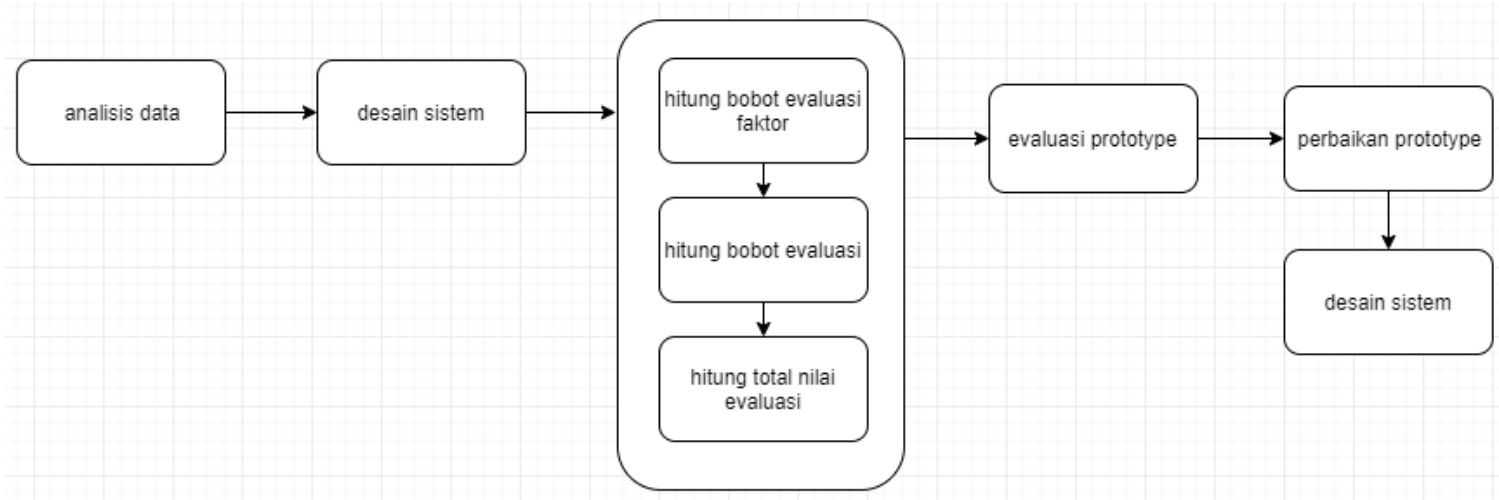

Gambar 1. Alur penelitian yang dilakukan

\section{Multi Factor Evaluation Process (MFEP)}

MFEP merupakan salah satu metode yang menggunakan weighting system melalui keputusan multi faktor terhadap kriteria dan alternative yang diberikan [9]. Dalam MFEP seluruh kriteria yang menjadi faktor penting akan diberikan bobot (weighting) sesuai dengan tingkat kepentingannya. Begitu pula untuk setiap alternatif, yang selanjutnya akan dievaluasi terkait faktor pertimbangan tersebut. Metode MFEP akan memilih alternative dengan nilai solusi tertinggi berdasarkan kriteria. MFEP[10]:

Berikut merupakan langkah-langkah proses perhitungan menggunakan metode

1. Menentukan faktor dan bobot faktor dimana total pembobotan harus sama dengan 1

$(\Sigma$ pembobotan $=1)$ yaitu factor weight. Adapun persamaan yang digunakan terdapat pada persamaan (1)

$E F=\frac{\sum x}{\sum x_{\max }}$

...persamaan (1)

Dimana:

EF : Evaluasi Faktor

$\mathrm{x} \quad$ : Nilai subkriteria

$\mathrm{x}_{\max } \quad$ : Nilai $\mathrm{x} \max$

2. Mengisikan nilai untuk setiap faktor yang mempengaruhi dalam pengambilan keputusan dari data-data yang akan diproses, nilai yang dimasukkan dalam proses pengambilan keputusan merupakan nilai objektif, yaitu sudah pasti yaitu factor evaluation yang nilainya antara 0 - 1. Adapun persamaan tersebut terlihat pada persamaan (2)

$W E=F W x E$

... persamaan (2)

Dimana :

WE : Nilai bobot evaluasi 
FW : Nilai bobot faktor

E : Nilai evaluasi faktor

3. Proses perhitungan weight evaluation yang merupakan proses perhitungan bobot antara factor weight dan factor evaluation dengan penjumlahan seluruh hasil weight evaluations untuk memperoleh total hasil evaluasi. Adapun persamaan tersebut terlihat pada persamaan (3)

$\sum_{i=1}^{n} W E_{i}=W E_{1}+W E_{2}+W E_{n}$

... persamaan (3)

Dimana:

$\sum_{i=1}^{n} W E i \quad$ : Total nilai evaluasi

$\mathrm{WE}_{\mathrm{i}} \quad$ : Nilai evaluasi ke - $\mathrm{i}$

\section{HASIL DAN PEMBAHASAN}

\section{Penerapan MFEP pada kasus}

Penerapan MFEP yang digunakan untuk menghitung total poin kegiatan mahasiswa terlihat pada gambar 2 .

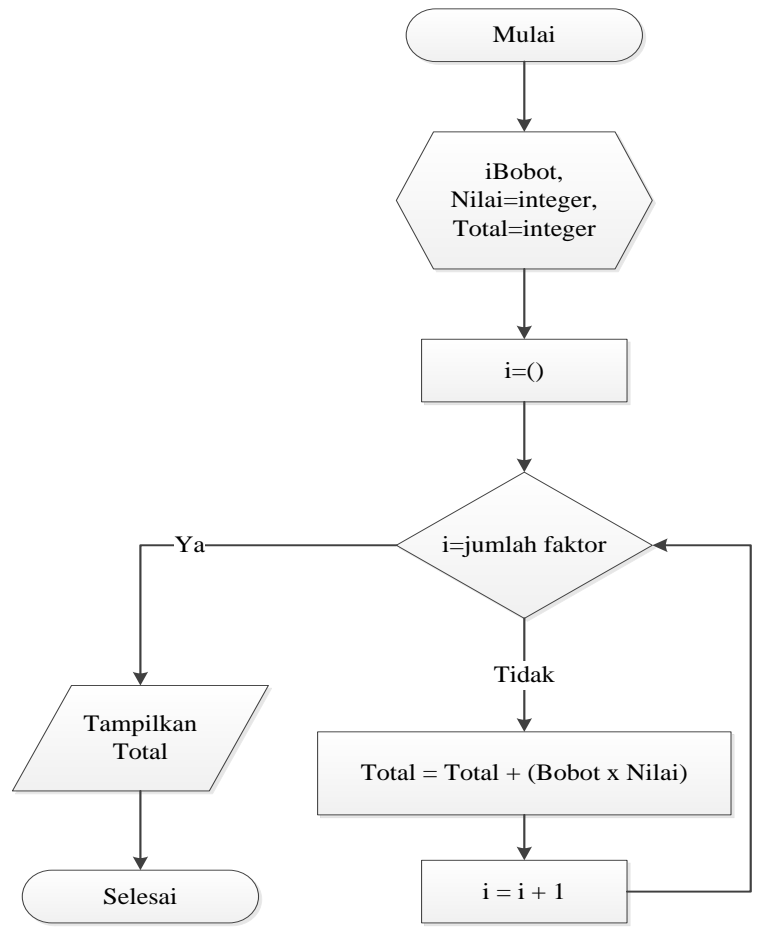

Gambar 2. Tahapan Multi Factor Evaluation Process (MFEP) mahasiswa:

Berikut ini penjabaran penerapan MFEP pada kasus penentuan jumlah poin SKKM

a. Tahap pertama yaitu menentukan bobot poin.

Pada tahap ini, peneliti akan memasukan nilai yang didapatkan dari Buku Pedoman Satuan Kredit Partisipasi Mahasiswa Universitas Catur Insan Cendekia Tahun 2018, adapun bobot poin terangkum pada Tabel 1. 
Table 1. Kriteria dan pembobotan poin kegiatan bidang penalaran / ilmiah

Kegiatan Bidang Penalaran / Ilmiah

\begin{tabular}{|c|c|c|c|}
\hline A. Lomba Ilmiah & Bobot & B. Kreativitas Mahasiswa/Pkm & Bobot \\
\hline Tingkat Lokal & Poin & 1. Juara Pimnas & Poin \\
\hline 1. Juara 1 & 8 & Ketua & 40 \\
\hline 2. Juara 2 & 5 & Anggota & 35 \\
\hline 3. Juara 3 & 3 & 2. Lolos Pimnas & \\
\hline 4. Finalis & 1 & Ketua & 35 \\
\hline & & Anggota & 30 \\
\hline
\end{tabular}

Pada lomba ilmiah tingkat lokal, pembobotan poin akan berdasarkan tingkatan juara yang diperoleh. Juara 1, 2, dan 3 akan memperoleh bobot 8, 5, dan 3. Sedangkan apabila hanya sebagai finalis maka akan mendapatkan poin 1. Sedangkan pada bidang kreativitas mahasiswa / PKM akan dilihat berdasarkan keikutsertaan mahasiswa dalam PIMNAS (Pekan Ilmiah Mahasiswa Nasional). Bobot pada PIMNAS akan lebih besar bila dibandingkan dengan lomba ilmiah lainya dimana jika berhasil menjuari PIMNAS maka akan mendapatkan poin 40 sebagai ketua dan 35 sebagai anggota, namun jika hanya berhasil lolos di PIMNAS maka akan mendapatkan poin 35 dan 30 sebagai ketua dan wakil ketua.

Sedangkan untuk pembobotan kegiatan bidang minat dan bakat mahasiwa terangkum pada Tabel 2. Untuk bidang ini, peneliti membagi menjadi 2 yaitu olahraga dan seni. Sedangkan tingkatannya akan dibagi menjadi tingkat prodi prodi/fakultas/universitas, tingkat provinsi/regional, nasional, dan internasional.

Table 2. Kriteria dan pembobotan poin pada kegiatan bidang minat dan bakat KEGIATAN BIDANG MINAT DAN BAKAT

\begin{tabular}{|c|c|c|c|}
\hline A. Lomba Olah Raga & Bobot & B. Lomba Seni & Bobot \\
\hline Tingkat Prodi/Fak/ Univ. & Poin & Tingkat Prodi/Fak/ Univ. & Poin \\
\hline 1. Juara 1 & 8 & 1. Juara 1 & 8 \\
\hline 2. Juara 2 & 5 & 2. Juara 2 & 5 \\
\hline 3. Juara 3 & 3 & 3. Juara 3 & 3 \\
\hline 4. Peserta & 1 & 4. Peserta & 1 \\
\hline Tingkat & & Tingkat & \\
\hline Provinsi/Regional & & Provinsi/Regional & \\
\hline 1. Juara 1 & 10 & 1. Juara 1 & 10 \\
\hline 2. Juara 2 & 8 & 2. Juara 2 & 8 \\
\hline 3. Juara 3 & 5 & 3. Juara 3 & 5 \\
\hline 4. Peserta & 2 & 4. $\quad$ Peserta & 2 \\
\hline Tingkat Nasional & & Tingkat Nasional & \\
\hline 1. Juara 1 & 20 & 1. Juara 1 & 20 \\
\hline 2. Juara 2 & 17 & 2. Juara 2 & 17 \\
\hline 3. Juara 3 & 14 & 3. Juara 3 & 14 \\
\hline 4. $\quad$ Peserta & 8 & 4. Peserta & 8 \\
\hline Tingkat Internasional & & Tingkat Internasional & \\
\hline 1. Juara 1 & 25 & 1. Juara 1 & 25 \\
\hline 2. Juara 2 & 22 & 2. Juara 2 & 22 \\
\hline 3. Juara 3 & 18 & 3. Juara 3 & 18 \\
\hline 4. Peserta & 10 & 4. Peserta & 10 \\
\hline
\end{tabular}

Sedangkan untuk kriteria dan pembobotan poin kegiatan bidang organisasi dan kepanitiaan terangkum pada Tabel 3. Untuk kepengurusan lembaga mahasiswa hanya dilihat berdasarkan tingkat Universitas, sedangkan untuk kepanitiaan akan dinilai untuk tingkat universitas dan fakultas. 
Table 3. Kriteria dan pembobotan poin kegiatan bidang organisasi dan kepanitiaan KEGIATAN BIDANG ORGANISASI DAN KEPANITIAAN

\begin{tabular}{|c|c|c|c|}
\hline \multirow{2}{*}{$\begin{array}{l}\text { A. Pengurus Lembaga Mahasiswa } \\
\text { Tingkat Universitas }\end{array}$} & \multirow{2}{*}{$\begin{array}{l}\text { Bobot } \\
\text { Poin }\end{array}$} & B. Kepanitiaan & \multirow{2}{*}{$\begin{array}{l}\text { Bobot } \\
\text { Poin }\end{array}$} \\
\hline & & Tingkat Universitas & \\
\hline 1. Presiden BKM & 20 & Ketua & 10 \\
\hline 2. Wakil Presiden BKM & 18 & Wakil Ketua & 9 \\
\hline 3. $\quad$ Sekretaris BKM & 17 & 3. $\quad$ Sekretaris & 8 \\
\hline 4. Bendahara BKM & 17 & 4. $\quad$ Bendahara & 8 \\
\hline 5. Menteri Kabinet BKM & 15 & 5. Koordinator Seksi & 7 \\
\hline 6. Wakil Menteri Kabinet BKM & 14 & 6. Anggota Panitia & 5 \\
\hline 7. Anggota Pengurus BKM & 10 & Tingkat Fakultas & \\
\hline 8. Ketua DPM & 15 & Ketua & 10 \\
\hline 9. Wakil Ketua DPM & 13 & 2. Wakil Ketua & 9 \\
\hline 10. Sekretaris DPM & 12 & 3. Sekretaris & 8 \\
\hline 11. Bendahara DPM & 12 & 4. Bendahara & 8 \\
\hline 12. Anggota Pengurus DPM & 10 & 5. $\quad$ Koordinator Seksi & 7 \\
\hline 13. Ketua UKM & 10 & 6. Anggota Panitia & 5 \\
\hline
\end{tabular}

Sedangkan untuk kriteria dan pembobotan poin bidang pengabdian masyarakat terangkum pada Tabel 4.

Table 4. Kriteria dan pembobotan poin kegiatan bidang pengabdian pada masyarakat

\begin{tabular}{llc}
\hline \multicolumn{2}{c}{ KEGIATAN BIDANG PENGABDIAN PADA } \\
MASYARAKAT
\end{tabular}

b. Selanjutnya akan dihitung evaluasi faktor pada alternative sesuai dengan persamaan 2. Hasil perhitungan tersebut selanjutnya terdapat pada Tabel 5.

Table 5. Nilai evaluasi faktor

\begin{tabular}{cccccc}
\hline Kriteria & Mhs 01 & Mhs 02 & Mhs 03 & Mhs 04 & Mhs 05 \\
\hline C001 & 6 & 10 & 8 & 7 & 5 \\
\hline C002 & 7 & 6 & 9 & 6 & 5 \\
\hline C003 & 7 & 7 & 6 & 8 & 8 \\
\hline C004 & 9 & 6 & 8 & 7 & 6 \\
\hline
\end{tabular}

c. Selanjutnya akan dihitung total nilai evaluasi sesuai dengan persamaan 3. Sebelum mendapatkan totalnya, maka akan dihitung terlebih dahulu bobot evaluasi dari masingmasing alternative. Table 6 adalah perhitungan untuk alternative 1. Berdasarkan Tabel 6 didapatkan informasi bahwa untuk mahasiswa 1 memiliki total bobot evaluasi sebesar 7,19.

Table 6. Evaluasi mahasiswa 1

\begin{tabular}{ccccc}
\hline Kriteria & $\begin{array}{c}\text { Bobot } \\
\text { faktor }\end{array}$ & & $\begin{array}{c}\text { Evaluasi } \\
\text { factor }\end{array}$ & $\begin{array}{c}\text { Bobot } \\
\text { evaluasi }\end{array}$ \\
\hline $\mathrm{C} 001$ & 0,25 & $\mathrm{X}$ & 6 & 1,5 \\
\hline $\mathrm{C} 002$ & 0,16 & $\mathrm{X}$ & 7 & 1,12 \\
\hline $\mathrm{C} 003$ & 0,37 & $\mathrm{X}$ & 7 & 2,59 \\
\hline C004 & 0,22 & $\mathrm{X}$ & 9 & 1,98 \\
\hline TOTAL & $\mathbf{1}$ & & & $\mathbf{7 , 1 9}$ \\
\hline
\end{tabular}

Untuk alternative 2, maka perhitungannya terdapat pada Tabel 7. Berdasarkan table 7 didapatkan informasi bahwa total bobot evaluasi untuk mahasiswa ke-2 adalah 7,37 
Table 7. Evaluasi mahasiswa 2

\begin{tabular}{ccccc}
\hline Kriteria & $\begin{array}{c}\text { Bobot } \\
\text { faktor }\end{array}$ & $\begin{array}{c}\text { Evaluasi } \\
\text { factor }\end{array}$ & $\begin{array}{c}\text { Bobot } \\
\text { evaluasi }\end{array}$ \\
\hline $\mathrm{C} 001$ & 0,25 & $\mathrm{X}$ & 10 & 2,5 \\
\hline $\mathrm{C} 002$ & 0,16 & $\mathrm{X}$ & 6 & 0,96 \\
\hline $\mathrm{C} 003$ & 0,37 & $\mathrm{X}$ & 7 & 2,59 \\
\hline C004 & 0,22 & $\mathrm{X}$ & 6 & 1,32 \\
\hline TOTAL & $\mathbf{1}$ & & & $\mathbf{7 , 3 7}$ \\
\hline
\end{tabular}

Hal yang sama juga dilakukan untuk alternative 3 dan 4. Sehingga didapatkan hasil keseluruhan untuk masing-masing alternative seperti Tabel 8. Perhitungan total keseluruhan ini merupakan hasil perhitungan berdasarkan persamaan 3

Table 8. Nilai perangkingan

\begin{tabular}{|c|c|c|}
\hline Kriteria & Total & Rangking \\
\hline Mhs 01 & 7,19 & 4 \\
\hline Mhs 02 & 7,37 & 2 \\
\hline Mhs 3 & 7,42 & 1 \\
\hline Mhs 4 & 7,21 & 3 \\
\hline Mhs 5 & 6,33 & 5 \\
\hline
\end{tabular}

berdasarkan table 8 diketahui bahwa mahasiswa 3 merupakan mahasiswa yang memiliki nilai SKKM tertinggi sehingga dapat dikatakan mahasiswa tersebut lebih aktif bila dibandingkan dengan mahasiswa lainnya dalam kegiatan ektrakulikuler kampus.

\section{Implementasi}

Setelah dilakukan perancangan sistem, maka langkah selanjutnya yaitu melakukan pembuatan prototype dari sistem yang dibuat. Beberapa form yang dibuat adalah:

a. Halaman Login

Pada Gambar 3 berisikan tampilan Login untuk user (Mahasiswa, Kabag Kemahasiswaan dan Kepala Program Studi). Pada tampilan ini terdapat form input user id dan password.

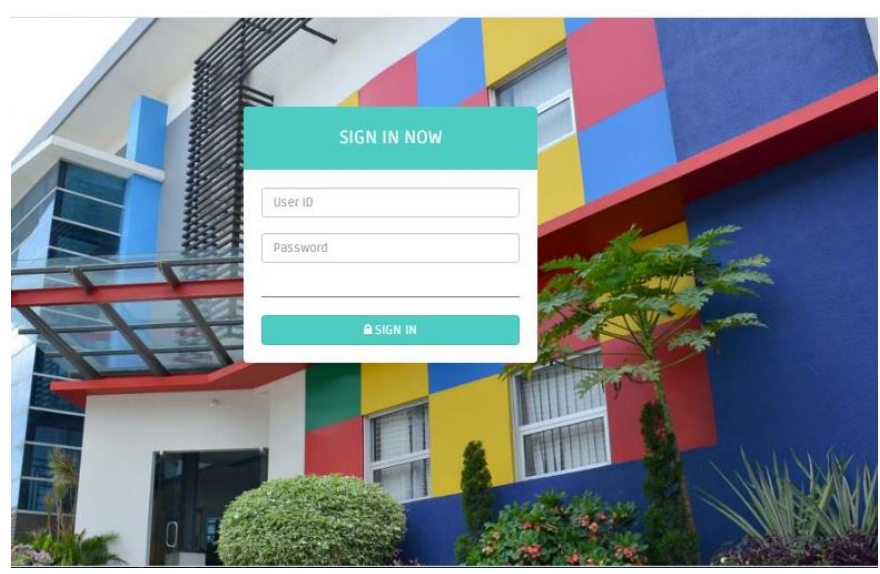

Gambar 3. Halaman login user

b. Halaman Kelola Kegiatan Akademik

Pada Gambar 4 berisikan tampilan halaman kelola kegiatan akademik untuk SKKM untuk mahasiswa. 


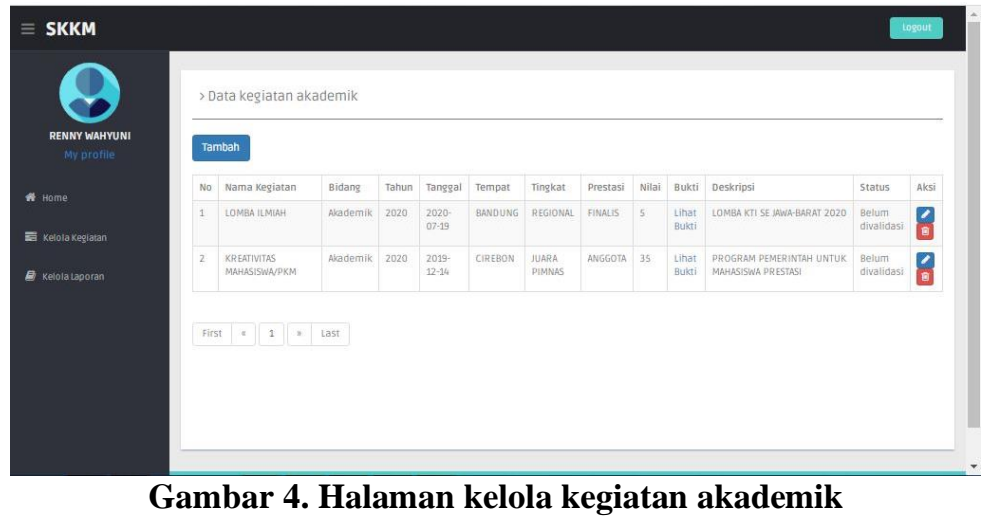

c. Halaman Laporan SKKM

Pada Gambar 5, 6 dan 7 merupakan tampilan laporan berisikan tampilan halaman kelola kegiatan akademik untuk SKKM untuk mahasiswa. Pada Gambar 5 merupakan output yang digunakan untuk melihat laporan hasil kinerja mahasiswa yaitu Laporan Rekapitulasi Satuan Kredit Kegiatan Mahasiswa (SKKM).

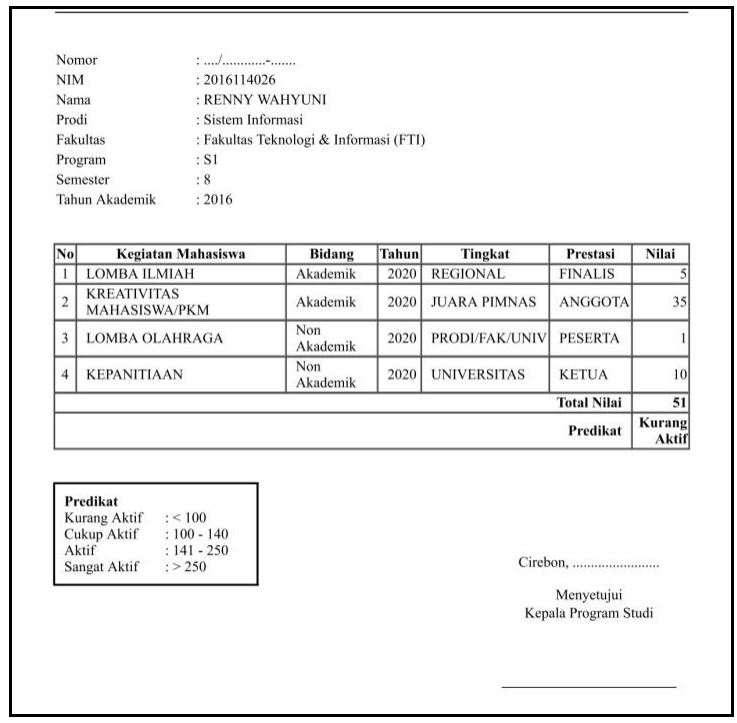

Gambar 5. Laporan rekapitulasi SKKM

Pada Gambar 4 Tampilan laporan akademik berisikan laporan hasil prestasi mahasiswa dibidang akademik setiap tahunnya.

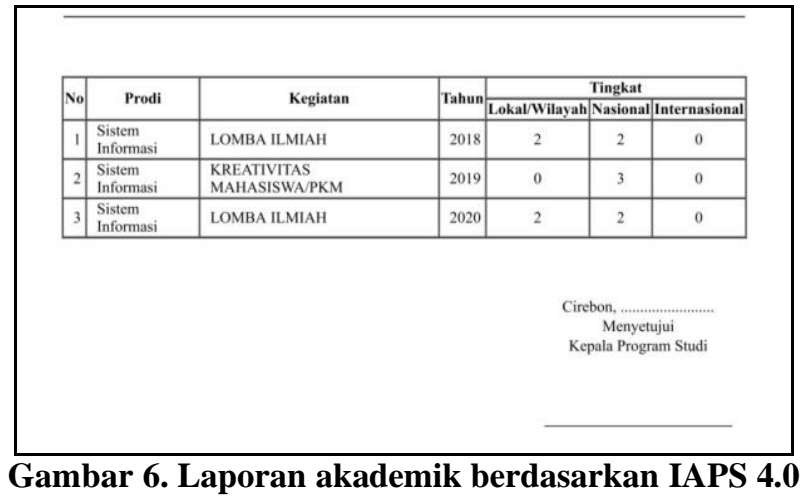

Pada Gambar 7 Tampilan laporan non akademik berisikan laporan hasil prestasi mahasiswa dibidang non akademik setiap tahunnya. 


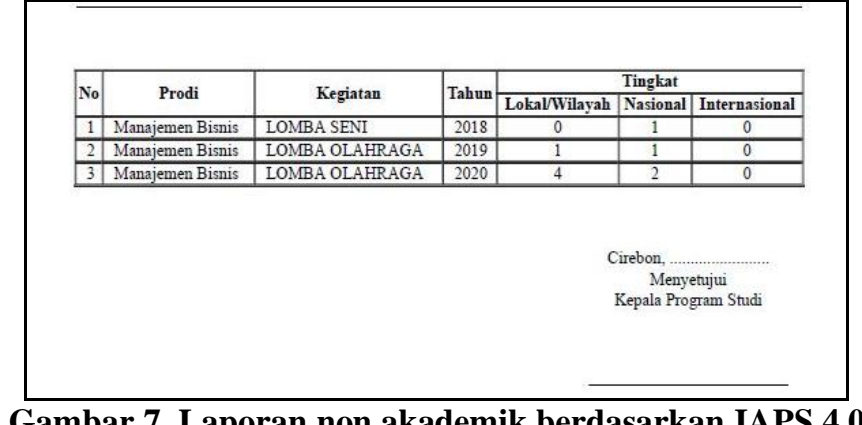

\section{Pengujian}

Pengujian yang dilakukan adalah menggunakan blackbox, untuk menguji fungsionalitas system yang dibuat. Hasil pengujian blackbox terangkum pada Tabel 9.

Table 9. Hasil pengujian blackbox

\begin{tabular}{|c|c|c|c|c|c|}
\hline No & Form uji & Data uji & Hasil yang diharapkan & Hasil pengamatan & Kesimpulan \\
\hline 1 & Form login & $\begin{array}{l}\text { Masukkan username } \\
\text { dengan angka dan } \\
\text { password tanpa "@”" }\end{array}$ & $\begin{array}{l}\text { Sistem menolak dan } \\
\text { mengeluarkan pesan } \\
\text { kesalahan, karena } \\
\text { username tidak boleh } \\
\text { angka, dan password } \\
\text { harus mengandung @ }\end{array}$ & $\begin{array}{l}\text { Sistem menolak dan } \\
\text { menampilkan pesan } \\
\text { kesalahan }\end{array}$ & Sesuai \\
\hline 2 & $\begin{array}{l}\text { Kelola } \\
\text { kegiatan } \\
\text { akademik }\end{array}$ & $\begin{array}{l}\text { Nama kegiatan dan } \\
\text { tempat kegiatan tidak } \\
\text { boleh mengandung } \\
\text { angka }\end{array}$ & $\begin{array}{l}\text { sistem menampilkan } \\
\text { pesan kesalahan,dan } \\
\text { tidak menyimpan data } \\
\text { tadi kedalam table }\end{array}$ & $\begin{array}{l}\text { Sistem menolak, data } \\
\text { gagal disimpan dalam } \\
\text { table }\end{array}$ & Sesuai \\
\hline 3 & $\begin{array}{l}\text { Laporan } \\
\text { rekapitulasi } \\
\text { SKKM }\end{array}$ & $\begin{array}{l}\text { Memilih satu } \\
\text { mahasiswa yang akan } \\
\text { ditampilkan datanya } \\
\text { pada } \quad \text { Laporan } \\
\text { rekapitulasi SKKM }\end{array}$ & $\begin{array}{l}\text { Sistem hanya } \\
\text { menampilkan data } \\
\text { mahasiswa yang dipilih }\end{array}$ & $\begin{array}{l}\text { Sistem hanya } \\
\text { menampilkan data } \\
\text { mahasiswa yang } \\
\text { terpilih }\end{array}$ & Sesuai \\
\hline 4 & $\begin{array}{l}\text { Laporan } \\
\text { akademik }\end{array}$ & $\begin{array}{l}\text { Menampilkan salah } \\
\text { satu prodi yang akan } \\
\text { ditampilkan tahun } \\
\text { akademiknya }\end{array}$ & $\begin{array}{l}\text { Sistem hanya } \\
\text { menampilkan data prodi } \\
\text { berdasarkan tahun } \\
\text { akademik yang dipilih }\end{array}$ & $\begin{array}{l}\text { Sistem hanya } \\
\text { menampilkan data } \\
\text { prodi dan tahun } \\
\text { akademiknya }\end{array}$ & Sesuai \\
\hline 5 & $\begin{array}{l}\text { Laporan non } \\
\text { akademik }\end{array}$ & $\begin{array}{lr}\text { Menampilkan } & \text { salah } \\
\text { satu prodi yang akan } \\
\text { ditampilkan tahun } \\
\text { akademiknya }\end{array}$ & $\begin{array}{l}\text { Sistem hanya } \\
\text { menampilkan data prodi } \\
\text { berdasarkan tahun } \\
\text { akademik yang dipilih }\end{array}$ & $\begin{array}{l}\text { Sistem hanya } \\
\text { menampilkan data } \\
\text { prodi dan tahun } \\
\text { akademiknya }\end{array}$ & Sesuai \\
\hline
\end{tabular}

\section{KESIMPULAN}

Berdasarkan hasil penelitian dan analisa serta perancangan yang telah dilaksanakan, maka dapat ditarik kesimpulan bahwa dengan adanya Aplikasi Satuan Kredit Kegiatan Mahasiswa (SKKM) dapat membantu Universitas dalam merangking keaktifan mahasiswa dikampus. Dan dengan dibuatnya Aplikasi SKKM, pendokumentasian kegiatan akademik dan non akademik mahasiswa menjadi lebih mudah. Kemudahan ini juga dirasakan oleh Kepala Program Studi untuk memenuhi salah satu kriteria Intrumen Akreditasi Program Studi (IAPS) 4.0 yaitu kriteria Sembilan - Luaran dan Capaian Tridharma. 


\section{DAFTAR PUSTAKA}

[1] P. L. Santiari, "Penggunaan Metode Fuzzy Dalam Penilaian Tingkat Kemampuan NonAkademik Mahasiswa Melalui Satuan Kredit Kegiatan Mahasiswa," J. Teknol. Inf. dan Ilmu Komput., vol. 3, no. 4, pp. 253-258, 2016, doi: 10.25126/jtiik.201634182.

[2] M. Agustina, "Implementasi Metode Multi Factor Evaluation Process (MFEP) Dalam Membuat Keputusan Untuk Memilih Asuransi Kesehatan,” J. Ilm. Matrik, vol. 21, no. 2, pp. 108-117, 2019, doi: 10.33557/jurnalmatrik.v21i2.574.

[3] R. Purnomo, A. Nurdin, and J. Nangi, "Penerapan Multifactor Evaluation Process (MFEP) Untuk Penilaian Guru (Studi Kasus: Man 1 Kota Kendari)," Semin. Nas. Ris. Kuantitatif Terap., no. April, pp. 76-79, 2017, [Online]. Available: http://ojs.innovcenter.org/index.php/snrkt2017/article/view/13/12.

[4] S. H. Mulyani, "Rancang Bangun Sistem Informasi Sistem Kredit Partisipasi Aktivitas Mahasiswa (Siskpam)," J. Sist. Inf., vol. 8, no. 2, pp. 1069-1079, 2016, [Online]. Available: https://ejournal.unsri.ac.id/index.php/jsi/article/view/3643/1923.

[5] A. Rasyid, F. Pradana, and D. S. Rusdianto, "Pembangunan Sistem Informasi Pengajuan Kegiatan dan Pemberian Poin Bagi Mahasiswa Fakultas Ilmu Komputer Universitas Brawijaya," J. Pengemb. Teknol. Inf. dan Ilmu Komput., vol. 2, no. 9, pp. 3409-3415, 2018, [Online]. Available: http://j-ptiik.ub.ac.id/index.php/j-ptiik/article/view/2294.

[6] I. G. A. S. Dharma, D. C. Khrisne, and I. M. A. Suyadnya, "Rancang Bangun Sistem Informasi Satuan Kredit Partisipasi Mahasiswa Fakultas Teknik Universitas Udayana," Spektrum, vol. 4, no. 2, pp. 81-88, 2017, [Online]. Available: https://ojs.unud.ac.id/index.php/spektrum/article/download/36416/21991.

[7] R. B. Kucorojati and K. Haryono, "Pengembangan Sistem Satuan Kredit Partisipasi Modul Pengelola Studi Kasus Universitas Islam Indonesia," Automata, vol. 1, no. 2, 2020, [Online]. Available: https://journal.uii.ac.id/AUTOMATA/article/view/15571.

[8] Ronida and Kosim, "Implementasi Prototype Dalam Pembuatan Website Sebagai Media Promosi Di MA Darul Masholeh CiIrebon," J. Ilm. Intech Informatioan Technol. J. UMUS, vol. 1, no. 2, pp. 33-42, 2019, [Online]. Available: http://jurnal.umus.ac.id/index.php/intech/article/view/68/48.

[9] A. K. Vadreas, R. Turaina, and S. Ardiansyah, "Sistem Penunjang Keputusan Penentuan (SPK) Bantuan Dana Pembangunan Rumah Tidak Layak Huni (RTLH) Dengan Metode Multi Factor Evoluation Process (MFEP)," J. Teknoif, vol. 6, no. 1, pp. 18-23, 2018, doi: 10.21063/jtif.2018.v6.1.18-23.

[10] D. Saripurna, "Sistem Pendukung Keputusan Dalam Menentukan Kualitas Kopi Arabica Layak Ekspor Pada Pt . Indo Cafco Dengan Metode Multi Factor Evaluation Process," Sains dan Komput., vol. 17, no. 2, pp. 234-238, 2018, [Online]. Available: https://ojs.trigunadharma.ac.id/index.php/jis/article/view/109/61. 